\title{
Universal Combustion Chamber for Utilization of Petroleum Gases of Different Composition and Heat Output
}

\author{
Shilova A.A., Bachev N.L., Matyunin O.O. \\ Perm National Research Polytechnic University \\ Perm, Russia
}

\begin{abstract}
When developing micro-gas turbine power plants, it is necessary to have universal two-zone combustion chambers for utilizing petroleum gases of different composition and heat output at different oil deposits. In the combustion zone, the excess air ratio is selected from the interval between the lower and upper concentration limits of combustion. In the dilution zone by supplying secondary air, the working fluid with specified parameters is prepared for supply to the turbine. The excess air coefficient at the exit from the combustion chamber is determined from the energy balance equation and depends on the air and fuel gas parameters at the entrance to the combustion chamber and on the temperature of the working fluid at the entrance to the turbine. The purpose of this work is to develop recommendations for creating a universal combustion chamber for combustion of fuel gases of different composition and heat output. This goal is achieved by selecting the diameter of the chamber in order to ensure the required ratios between the average flow rate of the combustible air mixture and the rate of turbulent combustion, at which a stable position of the flame front is observed. The most noticeable result of the research conducted is substantiation of the possibility of using a universal combustion chamber with constant dimensions in utilization gas turbine installations designed for burning nonstandard fuel gases with ballasting components content up to $70 \%$, which will reduce the time and cost of development and implementation of these installations.

Keywords: ballasted petroleum gas, diameter of the universal combustion chamber, flame front stable position, power range of power plants.

DOI: https://doi.org/10.52254/1857-0070.2021.1-49.12

UDC: 665.612 .2
\end{abstract}

Cameră de ardere universală pentru utilizarea gazelor petroliere cu diferite compoziții și putere termică Şilova A.A., Bacev N.L., Matiunin O.O.

Universitatea Națională Politehnică de cercetare din Perm

Perm, Federația Rusă

Rezumat. În proces de elaborare a centralelor electrice de utilizare a instalațiillor de microturbine cu recuperare cu gaze, este necesar să se aibă în componența lor camere de ardere universale cu două zone lor pentru utilizarea gazelor petroliere cu compoziție diferită și putere termică dîn diferite zăcământe. În zona de ardere, arderea stabilă a gazului de petrol cu balast are loc la temperaturi ridicate. Debitele de aer și gaz combustibil din această zonă sunt selectate în aşa fel încât să se asigure excesul de raport de aer în intervalul dintre limitele de concentrație inferioară și superioară de ardere. Studiile preliminare au arătat că pentru gazele petroliere cu un conținut de component de balastare de până la $80 \%$, excesul de coeficient de aer din zona de ardere poate fi luat egal cu 1.5. În zona de diluare prin furnizarea de aer secundar, fluidul de lucru este preparat cu parametrii specificați pentru alimentarea turbinei. Scopul acestei lucrări este de a elabora recomandări pentru crearea unei camere de ardere universale pentru arderea gazelor combustibile cu diferite compoziții și putere termică. Acest obiectiv este atins prin selectarea diametrului camerei pentru a asigura raporturile necesare între debitul mediu al amestecului de aer combustibil și rata de ardere turbulentă, la care se respectă o poziție stabilă a frontului flăcării. Rezultatul cel mai semnificativ al cercetării este confirmarea posibilității de utilizare a unei camere de ardere universale cu dimensiuni constante în instalațiile de utilizare a turbinei cu gaz concepute pentru arderea gazelor combustibile nestandardizate cu componente de balastare până la 70\%, ceea ce va reduce timpul și costul a implementării lor.

Cuvinte-cheie: gaz petrolier balastat, diametrul camerei de ardere universale, poziția stabilă a frontului flăcării, gama de putere a centralelor electrice.

(C) Шилова А.А., Бачев Н.Л.,

Матюнин O.O., 2021 


\section{Универсальная камера сгорания для утилизации разнородных по составу и теплопроизводительности нефтяных газов \\ Шилова А.А., Бачев Н.Л., Матюнин О.О.}

Пермский национальный исследовательский политехнический университет Пермь, Российская Федерация

Аннотация. При разработке отечественных микрогазотурбинных утилизационных энергоустановок необходимо иметь в их составе универсальные двухзонные камеры сгорания для утилизации разнородных по составу и теплопроизводительности нефтяных газов на разных месторождениях. В зоне горения происходит устойчивое горение забалластированного нефтяного газа при высоких температурах. Расходы воздуха и топливного газа в эту зону выбираются таким образом, чтобы обеспечить коэффициент избытка воздуха в интервале между нижним и верхним концентрационными пределами горения. Предварительные исследования показали, что для нефтяных газов с содержанием балластирующих компонентов до 80 \% коэффициент избытка воздуха в зоне горения может быть принят равным 1.5. В зоне разбавления подводом вторичного воздуха происходит подготовка рабочего тела с заданными параметрами для подачи на турбину. Коэффициент избытка воздуха на выходе из камеры сгорания определяется из уравнения энергетического баланса и зависит от температуры воздуха, состава, теплопроизводительности и температуры топливного газа на входе в камеру сгорания, от температуры рабочего тела на входе в турбину и от режимных параметров применяемых турбокомпрессоров в составе газотурбинной установки. Целью настоящей работы является выработка рекомендаций по созданию универсальной камеры сгорания для сжигания разнородных по составу и теплопроизводительности топливных газов. Указанная цель достигается подбором диаметра камеры, с целью обеспечения потребных соотношений между среднерасходной скоростью горюче-воздушной смеси и скоростью турбулентного горения, при которых наблюдается стабильное положение фронта пламени. Наиболее значимым результатом проведенных исследований является обоснование возможности использования универсальной камеры сгорания с постоянными размерами в утилизационных газотурбинных установках, предназначенных для сжигания нестандартных топливных газов с содержанием балластирующих компонентов до 70\%, что позволит сократить время и стоимость их внедрения.

Ключевые слова: забалластированный нефтяной газ, диаметр универсальной камеры сгорания, устойчивое положение фронта пламени, мощностной ряд энергоустановок.

\section{ВВЕДЕНИЕ}

Разработки отечественного утилизационного микротурбинного энергоагрегата требуют создания универсальной двухзонной камеры сгорания (КС) для сжигания разнородных по составу и теплопроизводительности топливных газов. В соответствии с результатами исследований по концентрационным пределам горения нефтяных газов (НГ) с различным содержанием балластирующих компонентов $[1,2,3,4,5]$ предложено выбирать в первичной зоне двухзонной КС коэффициент избытка воздуха равный 1,5. Значение коэффициента избытка воздуха в зоне разбавления на выходе из двухзонной КС зависит от параметров подачи воздуха и топливного газа в камеру сгорания, от теплопроизводительности и состава топливного газа и от параметров подачи рабочего тела в сопловой аппарат турбины. Кроме того, для стабильного положения фронта пламени при сжигании разнородных по составу и теплопроизводительности топливных газов необходимо соблюдать определенное соотношение между среднерасходной скоростью горюче-воздушной смеси (ГВС) и скоростью турбулентного горения.

Сегодня имеется большое количество экспериментальных исследований, посвященных вопросам стабилизации пламени $[6,7,8,9$, $10,11,12,13,14]$. В работах $[8,13,14]$ получены экспериментальные данные по влиянию добавки газообразного водорода в состав топливных композиций на стабилизацию фронта горения. Имеются также экспериментальные данные по влиянию закрутки потока в завихрителе на устойчивость горения [11]. Влияние геометрических размеров узлов подачи на устойчивость диффузионного горения исследовано в [12]. Расчетноэкспериментальные исследования [15] показывают влияние давления и температуры подачи ГВС на положение фронта пламени.

Численное моделирование диффузионного или гомогенного горения $[16,17,18,19,20$, $21,22]$ проводилось с целью исследования положения пламени при влиянии различных факторов на входе в КС. В работе [17] рассмотрено влияние условий в зоне обратных токов на характеристики горения. В [19] рассмотрены вопросы термоакустической неста- 
бильности в КС газотурбинных установок (ГТУ) при использовании газообразного водорода в качестве топлива. Прогнозированию пределов срыва диффузионных пламен посвящена работа [20]. Численное моделирование $[21,22]$ посвящено вопросам динамики поведения пламени в КС ГТУ.

Информационно-аналитический показал, что расчетно-экспериментальные исследования в основном были направлены на выяснения влияния отдельных факторов на стабильное положение фронта пламени. Только в отдельных работах $[12,20,21,22]$ делается попытка выработать критерии стабильности пламени.

Отличительной особенностью данной работы является рассмотрение стабильного положения фронта пламени с использованием соотношения между среднерасходной скоростью ГВС и скоростью турбулентного горения, которое комплексно учитывает влияние различных факторов. Предлагается определение геометрических размеров камеры для обеспечения устойчивого горения с использованием обобщенного параметра относительная расходонапряженность.

Целью данной работы является выработка рекомендаций по созданию универсальной КС для сжигания разнородных по составу и теплопроизводительности топливных газов. Для универсальной КС принципиальным является вопрос о стабильном положении фронта пламени при сжигании различных композиций нестандартных топливных газов разного состава с воздухом. Устойчивое положение фронта пламени зависит от соотношения между среднерасходной скоростью и скоростью турбулентного горения ГВС. В результате расчетов газодинамических характеристик турбулентного горения получены возможные диапазоны диаметров универсальной КС для мощностного ряда энергоустановок, при которых наблюдается стабильное положение фронта пламени.

\section{ТЕРМОХИМИЧЕСКОЕ МОДЕЛИРОВАНИЕ РАЗНОРОДНЫХ ПО СОСТАВУ И \\ ТЕПЛОПРОИЗВОДИТЕЛЬНОСТИ ЗАБАЛЛАСТИРОВАННЫХ ТОПЛИВНЫХ ГАЗОВ}

Для определения режимных и геометрических параметров универсальной утилизационной КС требуется информация об основных термохимических характеристиках не- стандартных топливных газов. В данной работе в качестве топливных газов рассматриваются метан и реальные НГ различных месторождений РФ. Составы рассматриваемых топливных газов приведены в таблице 1 .

Условная химическая формула топливного газа, заданного компонентным составом, имеет следующий вид $C_{\mathrm{ZC}} H_{\mathrm{ZH}} S_{\mathrm{ZS}} O_{\mathrm{ZO}} N_{\mathrm{ZN}}$.

Количество атомов $i$-го элемента $(i=C, H$, $S, O, N)$

$$
Z_{i}=\sum \sigma V_{j} Z_{i j}
$$

где $\sigma V_{j}$ - объемная доля $j$-го компонента в составе топливного газа; $Z_{i j}-$ количество атомов $i$-го элемента в молекуле $j$-ого компонента.

Массовый элементный состав топливного газа:

$$
\sigma m_{i}=\frac{A_{i} Z_{i}}{\sum A_{i} Z_{i}},
$$

где $A_{i}$ - атомная масса $i$-го элемента.

Массовое стехиометрическое соотношение между топливным газом и воздухом:

$$
K_{m 0}=\frac{\frac{8}{3} \cdot \sigma m_{C}^{\mathrm{rop}}+8 \cdot \sigma m_{H}^{\mathrm{rop}}+\sigma m_{S}^{\mathrm{rop}}-\sigma m_{O}^{\mathrm{rop}}}{\sigma m_{O}^{\mathrm{o \kappa}}-\frac{8}{3} \cdot \sigma m_{C}^{\mathrm{o \kappa}}-8 \cdot \sigma m_{H}^{\text {ок }}-\sigma m_{S}^{\text {ок }}} .
$$

Плотность нестандартного топливного газа:

$$
\rho=\sum \sigma V_{j} \rho_{j},
$$

где $\rho_{j}-$ плотность $j$-го компонента в составе топливного газа.

Массовая доля $j$-го компонента:

$$
\sigma m_{j}=\frac{\rho_{j}}{\rho} \sigma V_{j} .
$$

Теплопроизводительность, удельные изобарная и изохорная теплоемкости топливного газа вычисляются по формулам:

$$
\begin{aligned}
H u & =\sum \sigma m_{j} H u_{j}, \\
c_{p} & =\sum \sigma m_{j} c_{p j}, \\
c_{v} & =\sum \sigma m_{j} c_{v j},
\end{aligned}
$$

где $H u_{j}, c_{p j}, c_{v j}$ - теплопроизводительность, удельные изобарная и изохорная теп- 
лоемкости j-го компонента в составе топлив- ного газа.

Таблица $1^{1}$.

Составы нефтяных газов².

\begin{tabular}{|c|c|c|c|c|c|c|}
\hline & \multicolumn{5}{|c|}{$\begin{array}{c}\text { Tопливные газы } \\
\text { (Fuel gases) }\end{array}$} \\
\hline $\begin{array}{c}\text { Компонент, об. \%, } \\
\text { (Component, \% vol.) }\end{array}$ & 1 & 2 & 3 & 4 & 5 & 6 \\
\hline $\mathrm{CH}_{4}$ & 100 & 58.0 & 18.7 & 5.1 & 8.4 & 4.2 \\
\hline $\mathrm{C}_{2} \mathrm{H}_{6}$ & 0 & 7.2 & 15.2 & 3.1 & 5.1 & 2.0 \\
\hline $\mathrm{C}_{3} \mathrm{H}_{8}$ & 0 & 8.5 & 15.9 & 5.5 & 4.2 & 2.3 \\
\hline $\mathrm{C}_{4} \mathrm{H}_{10}$ & 0 & 7.0 & 7.4 & 9.8 & 1.7 & 1.5 \\
\hline $\mathrm{C}_{5} \mathrm{H}_{12}$ & 0 & 5.8 & 1.3 & 5.2 & 1.2 & 0.7 \\
\hline $\mathrm{C}_{6} \mathrm{H}_{14}$ & 0 & 0 & 0.3 & 0 & 0.4 & 0.2 \\
\hline $\mathrm{H}_{2} \mathrm{~S}$ & 0 & 0 & 0.3 & 0 & 0 & 0 \\
\hline $\mathrm{CO}_{2}$ & 0 & 3.0 & 0.9 & 4.7 & 0.3 & 0 \\
\hline $\mathrm{N}_{2}$ & 0 & 10.5 & 40.3 & 66.6 & 78.7 & 89.0 \\
\hline$\sigma V_{6}$ & 0 & 13.5 & 41.2 & 71.3 & 79 & 89 \\
\hline
\end{tabular}

Термохимические характеристики исследуемых топливных газов, рассчитанные по приведенному выше алгоритму, приведены в таблице 2.

Таблица $2^{3}$.

Термохимические характеристики нефтяных газов ${ }^{4}$.

\begin{tabular}{|c|c|c|c|c|c|c|c|}
\hline № & $\begin{array}{c}\sigma V_{\sigma}, \\
\text { об. \% } \\
\text { \% vol. })\end{array}$ & $K_{m 0}$ & $\begin{array}{c}H u, \\
\text { МДж/кг } \\
(\mathrm{MJ} / \mathrm{kg})\end{array}$ & $\begin{array}{c}c_{p}, \\
\text { Дж/кгК } \\
(\mathrm{J} / \mathrm{kgK})\end{array}$ & $\begin{array}{c}c_{v}, \\
\text { Дж/кгК } \\
(\mathrm{J} / \mathrm{kgK})\end{array}$ & $\begin{array}{c}R, \\
\text { Дж/кгК } \\
(\mathrm{J} / \mathrm{kgK})\end{array}$ & $k$ \\
\hline 1 & 0 & 15.544 & 50.1 & 2448 & 1928 & 520 & 1.27 \\
\hline 2 & 13.5 & 12.383 & 40.7 & 1970 & 1730 & 240 & 1.15 \\
\hline 3 & 41.2 & 9.008 & 30.4 & 1722 & 1464 & 258 & 1.18 \\
\hline 4 & 71.3 & 5.544 & 19.2 & 1448 & 1219 & 229 & 1.21 \\
\hline 5 & 79 & 3.394 & 11.9 & 1310 & 1025 & 285 & 1.28 \\
\hline 6 & 89 & 1.792 & 6.6 & 1190 & 900 & 290 & 1.32 \\
\hline
\end{tabular}

На рисунке 1 приведены графические зависимости $K_{m 0}=f\left(\sigma V_{\sigma}\right)$ и $H u=f\left(\sigma V_{\sigma}\right)$ для нефтяных газов с содержанием балластирующих компонентов до $90 \%$.
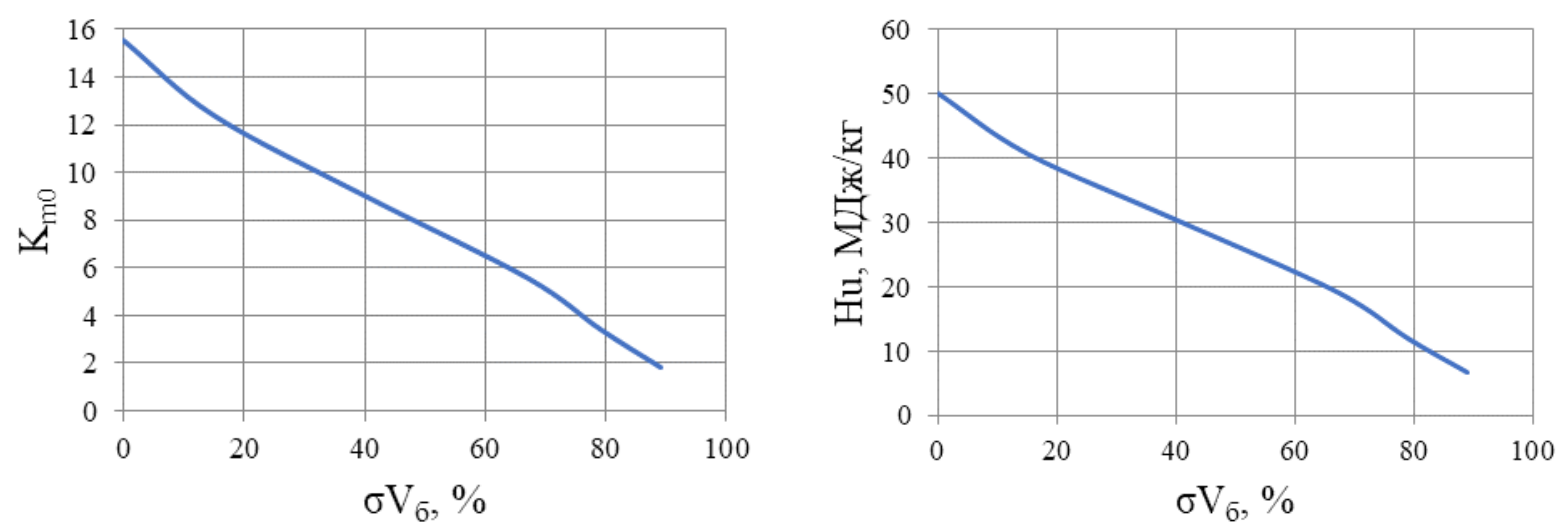

Рис.1. Влияние балластирующих компонентов на массовое стехиометрическое соотношение и теплопроизводительность нефтяных газов. ${ }^{5}$ 
Анализ показывает, что с увеличением содержания балластирующих компонентов массовое стехиометрическое соотношение уменьшается. Это объясняется необходимостью увеличенного подвода забалластированного топливного газа к единице объема топливо-воздушной смеси для получения заданных параметров горения. Теплопроизводительность топливного газа с увеличением содержания балластирующих компонентов уменьшается.
Коэффициенты избытка воздуха на верхнем и нижнем пределах горения определяются по методике, изложенной в работе [1]. Графические зависимости $\alpha_{u}=f\left(\sigma V_{\sigma}\right)$ и $\alpha_{\varepsilon}=f\left(\sigma V_{\sigma}\right)$ приведены на рисунке 2. Здесь же показан способ выбора коэффициента избытка воздуха $\alpha_{1}$ в зоне горения двухзонной КC.

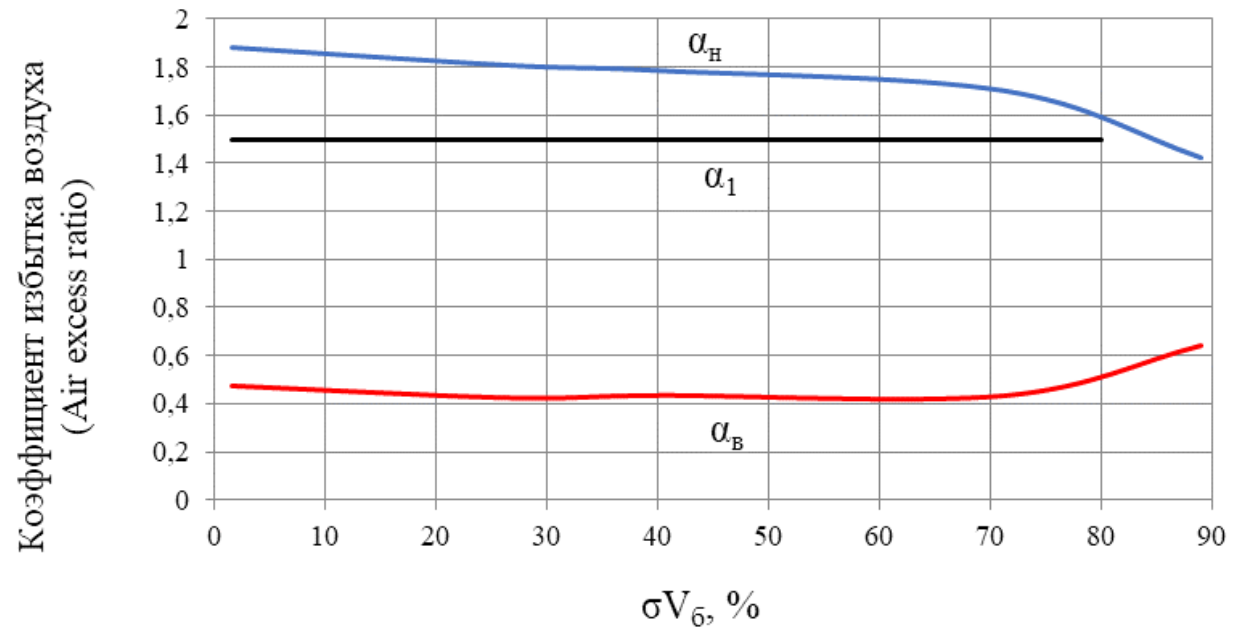

Рис.2. Влияние балластирующих компонентов на концентрационные пределы горения. ${ }^{6}$

При содержании балластирующих компонентов до $70 \%$ диапазон горения по концентрационным пределам находится при коэффициентах избытка воздуха $\alpha$ в среднем от 0.4 до 1.8. При содержании балластирующих компонентов более 70 \% диапазон воспламеняемости забалластированных газов начинает резко сокращаться. Следовательно, целесообразно разрабатывать универсальную КС для утилизации НГ с содержанием балластирующих компонентов до $70 \%$.

\section{ТЕРМОДИНАМИЧЕСКАЯ МОДЕЛЬ УТИЛИЗАЦИОННОЙ МИКРОГАЗОТУРБИННОЙ ЭНЕРГОУСТАНОВКИ}

Камера сгорания является подсистемой микрогазотурбинной энергоустановки, поэтому при определении режимных и геометрических параметров КС необходима информация о режимных параметрах всей установки.

Принципиальная схема микрогазотурбинной энергоустановки для утилизации нестандартных топливных газов представлена на рисунке 3.
Предлагается следующий алгоритм определения режимных параметров энергоустановки.

- Удельная работа сжатия на компрессоре по магистрали окислителя (воздуха):

$$
H_{\text {к.ок }}=c_{p \text { ок }} \cdot T_{\text {ок.вх }}^{\mathrm{k}} \cdot\left(\varepsilon^{\frac{k-1}{k}}-1\right) \cdot \frac{1}{\eta_{\mathrm{k}}},
$$

где $c_{p \text { ок }}, k-$ удельная изобарная теплоемкость и показатель адиабаты окислителя; $T_{\text {ок.вx }}^{\mathrm{k}}-$ температура окислителя на входе в компрессор; $\varepsilon, \eta_{\text {к }}-$ степень сжатия и КПД компрессора.

- Давление воздуха на входе в камеру сгорания:

$$
P_{\mathrm{oK} . \mathrm{Bx}}^{\mathrm{\kappa c}}=\sigma_{\mathrm{BHA}} \cdot P_{0} \cdot \varepsilon,
$$

где $\sigma_{\text {внА }}-$ коэффициент полноты давления во входном направляющем аппарате; $P_{0}-$ стандартное давление. 


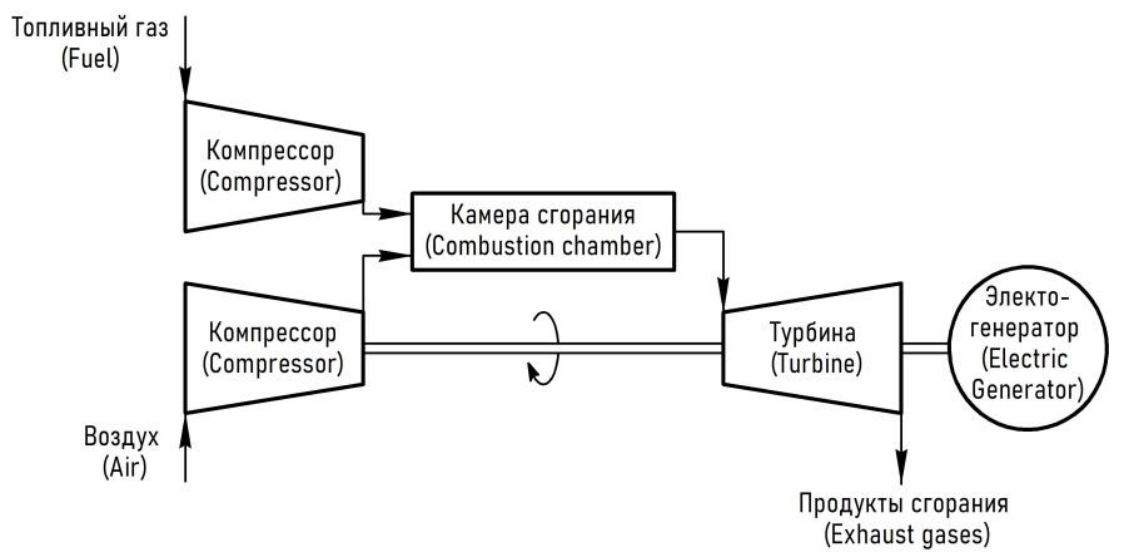

Рис.3. Принципиальные схемы микрогазотурбинной энергоустановки. ${ }^{7}$

- Температура воздуха на входе в камеру сгорания:

$$
T_{\text {ок.вх }}^{\mathrm{Kc}}=T_{0}+\frac{H_{\text {к.ок }}}{c_{p \text { ок }}},
$$

где $T_{0}$ - стандартная температура.

- Удельная работа сжатия на компрессоре по магистрали горючего (топливного газа):

$$
H_{\text {к.гор }}=c_{p \text { гор }} \cdot T_{\text {гор.вx }}^{\mathrm{K}} \cdot\left(\varepsilon^{\frac{k-1}{k}}-1\right) \cdot \frac{1}{\eta_{\mathrm{K}}},
$$

где $c_{p \text { гор }}, k-$ удельная изобарная теплоемкость и показатель адиабаты горючего; $T_{\text {гор.вх }}^{\mathrm{k}}-$ температура горючего на входе в компрессор; $\varepsilon, \eta_{\text {к }}$ - степень сжатия и КПД компрессора.

- Давление топливного на входе в камеру сгорания:

$$
P_{\text {rop..Bx }}^{\mathrm{rc}}=\sigma_{\mathrm{BHA}} \cdot P_{\mathrm{rop} . \mathrm{Bz}}^{\mathrm{\kappa}} \cdot \varepsilon,
$$

где $P_{\text {гор.вх }}^{\text {к }}-$ давление топливного газа на входе в компрессор.

- Температура топливного газа на входе в камеру сгорания:

$$
T_{\text {rop. } \mathrm{Bx}}^{\mathrm{rc}}=T_{\text {rop. Bx }}^{\mathrm{K}}+\frac{H_{\text {к. } \mathrm{rop}}}{c_{p \text { rop }}},
$$

где $T_{\text {rop.вx }}^{\mathrm{k}}-$ температура топливного газа на входе в компрессор.

- Коэффициент избытка воздуха на выходе из двухзонной КС, определяемый по параметрам ГТУ:

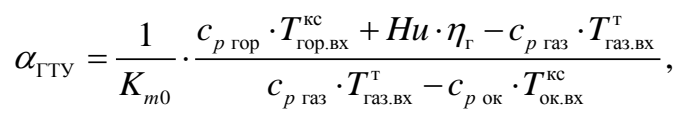

где $c_{p \text { газ }}, T_{\text {газвв }}^{\mathrm{T}}-$ удельная изобарная теплоемкость и температура рабочего тела на входе в турбину; $\eta_{\text {г }}$ - полнота сгорания топливного газа.

- Степень расширения на турбине:

$$
\delta=\lambda \cdot \varepsilon,
$$

где коэффициент потерь по газовоздушному тракту $(1-\lambda)=0,04 \ldots 0,07$.

- Удельная работа расширения на турбине:

$$
L_{\mathrm{T}}=c_{p \text { газ }} \cdot T_{\text {газ.в }}^{\mathrm{T}} \cdot\left(1-\frac{1}{\delta^{\frac{k-1}{k}}}\right) \cdot \eta_{\mathrm{T}},
$$

где $\eta_{\mathrm{\tau}}$ - КПД турбины.

- Давление рабочего тела на выходе из турбины:

$$
P_{\text {газ.вых }}^{\mathrm{T}}=\frac{P_{\text {ra3.вx }}^{\mathrm{T}},}{\delta},
$$

где $P_{\text {газвв }}^{\mathrm{\tau}}$ - давление рабочего тела на входе в турбину.

- Температура рабочего тела на выходе из турбины:

$$
T_{\text {газ.вых }}^{\mathrm{T}}=T_{\text {газ.вх }}^{\mathrm{T}}-\frac{L_{\mathrm{T}}}{c_{p \text { газ }}} .
$$

В традиционных микрогазотурбинных энергоустановках обычно используется двухзонная КС. В первичной зоне (зоне 
горения) обеспечивается устойчивое горение при коэффициенте избытка воздуха $\alpha_{l}$, который выбирается из интервала между верхним и нижним концентрационными пределами горения топливного газа. Для организации устойчивого горения в первичной зоне предлагается выбирать коэффициент избытка воздуха $\alpha_{1}$ вблизи нижнего предела горения (см. рис. 2).

- Полезная работа энергоустановки:

$$
L_{\text {пол }}=L_{\mathrm{T}}-H_{\text {к.ок }} \text {. }
$$

- Массовый расход рабочего тела через турбину для обеспечения эффективной мощности $N_{\text {пол }}$ :

$$
\dot{m}_{\text {газ }}=\frac{N_{\text {пол }}}{L_{\text {пол }}} .
$$

- Массовый расход топливного газа:

$$
\dot{m}_{\text {гор }}=\frac{\dot{m}_{\text {газ }}}{1+\alpha_{\text {Гту }} \cdot K_{m 0}} .
$$

- Суммарный массовый расход окислителя (воздуха):

$$
\dot{m}_{\text {ок }}=\dot{m}_{\text {газ }}-\dot{m}_{\text {гор }} .
$$

- Массовый расход воздуха в первичную зону:

$$
\dot{m}_{\text {ок } 1}=\alpha_{1} \cdot \dot{m}_{\text {гор }}
$$

- Массовый расход воздуха во вторичную зону:

$$
\dot{m}_{\mathrm{oK} 2}=\dot{m}_{\mathrm{oK}}-\dot{m}_{\text {ок } 1} .
$$

- Мощность, вырабатываемая турбиной:

$$
N_{\mathrm{T}}=\dot{m}_{\text {газ }} \cdot L_{\mathrm{T}} .
$$

- Потребная мощность на привод компрессора:

$$
N_{\mathrm{\kappa}}=\dot{m}_{\mathrm{o \kappa}} \cdot H_{\mathrm{\kappa}} .
$$

- Коэффициент полезной мощности:

$$
\varphi=\frac{N_{\text {пол }}}{N_{\text {т }}} .
$$

- Коэффициент полезного действия энергоустановки:

$$
\eta_{\text {Гту }}=\frac{N_{\text {пол }}}{\dot{m}_{\text {гор }} \cdot H u} .
$$

Суммарный расход в зоне горения:

$$
\dot{m}_{1}=\dot{m}_{\text {ок } 1}+\dot{m}_{\text {гор }}
$$

- Диаметр камеры сгорания, при котором обеспечивается устойчивое положение фронта пламени:

$$
D_{\mathrm{K}}=\sqrt{\frac{4 \cdot \dot{m}_{1}}{\pi \cdot g_{\mathrm{K}} \cdot P_{\mathrm{K}}}},
$$

где $P_{\text {к }}$ - давление в камере сгорания; по условиям устойчивости внутрикамерного рабочего процесса относительная расходонапряженность $g_{\mathrm{K}}=(0.8 \ldots .2 .5) \cdot 10^{-4} \mathrm{\kappa} / \mathrm{c} \cdot \mathrm{H}$.

\section{РЕЖИМНЫЕ И ГЕОМЕТРИЧЕСКИЕ ХАРАКТЕРИСТИКИ УНИВЕРСАЛЬНОЙ КС ДЛЯ УТИЛИЗАЦИИ НГ С \\ РАЗЛИЧНЫМ СОДЕРЖАНИЕМ \\ БАЛЛАСТИРУЮЩИХ КОМПОНЕНТОВ}

Расходные характеристики воздуха и топливного газа для ГТУ заданной мощности будут зависеть от коэффициента избытка

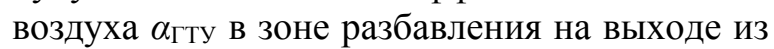
двухзонной КС. В таблице 3 приведены

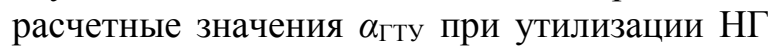
разного состава (табл.1) для утилизационной энергоустановки с турбокомпрессорами разного типа при степенях сжатия $\varepsilon=1.8$ и $\varepsilon=3.0$.

При расчетах $\alpha_{\text {гту учитывались }}$ температура воздуха на входе в КС $T_{\text {ок.вх }}^{\text {кс }}=f\left(\varepsilon, \sigma V_{\sigma}\right), \quad$ температура топливного газа на входе в $\mathrm{KC} \quad T_{\text {гор.вх }}^{\text {кс }}=f\left(\varepsilon, \sigma V_{\sigma}\right)$, теплопроизводительность $\quad H u=f\left(\sigma V_{\sigma}\right)$, массовое стехиометрическое соотношение $K_{m 0}=f\left(\sigma V_{\text {б}}\right)$ при заданной температуре рабочего тела на входе в неохлаждаемую турбину $T_{\text {газ.в }}^{\mathrm{T}}=1200 \mathrm{~K}$. 
Таблица $3^{8}$.

Расчетные значения коэффициента избытка воздуха $\alpha_{\text {гту }} 9$.

\begin{tabular}{|c|c|c|c|c|c|c|c|}
\hline \multirow{2}{*}{$\begin{array}{c}\sigma V_{6}, \\
\text { об. \% } \\
(\% \text { vol. })\end{array}$} & \multicolumn{2}{|c|}{$T_{\text {rop.BX }}^{\mathrm{Kc}}, \mathrm{K}$} & \multicolumn{2}{|c|}{$T_{\text {ок. } \mathrm{BX}}^{\mathrm{Kc}}, \mathrm{K}$} & \multirow{2}{*}{$T_{\text {ra3.,Bx }}^{\mathrm{T}}, K$} & \multicolumn{2}{|c|}{$\alpha_{\text {ГТу }}$} \\
\hline & $\varepsilon=1.8$ & $\varepsilon=3.0$ & $\varepsilon=1.8$ & $\varepsilon=3.0$ & & $\varepsilon=1.8$ & $\varepsilon=3.0$ \\
\hline 0 & 324.7 & 361.7 & 346.5 & 406.0 & 1200 & 3.13 & 3.34 \\
\hline 13.5 & 310.1 & 331.5 & 346.5 & 406.0 & 1200 & 3.17 & 3.38 \\
\hline 41.2 & 313.5 & 338.4 & 346.5 & 406.0 & 1200 & 3.23 & 3.44 \\
\hline 71.3 & 318.1 & 347.8 & 346.5 & 406.0 & 1200 & 3.25 & 3.46 \\
\hline 79 & 325.8 & 364.1 & 346.5 & 406.0 & 1200 & 3.18 & 3.40 \\
\hline 89 & 330.7 & 374.5 & 346.5 & 406.0 & 1200 & 3.10 & 3.32 \\
\hline
\end{tabular}

На рисунке 4 представлены графические зависимости температуры топливного газа на входе в КС от содержания балластирующих компонентов для газотурбинных энергоустановок с двумя типами турбокомпрессоров со степенями сжатия $\varepsilon=1.8$ и $\varepsilon=3.0$.
Сложный характер этих зависимостей объясняется тем, что теплофизические характеристики $\left(k, c_{p}, R\right)$ сильно зависят от состава реальных НГ (см. табл. 2).

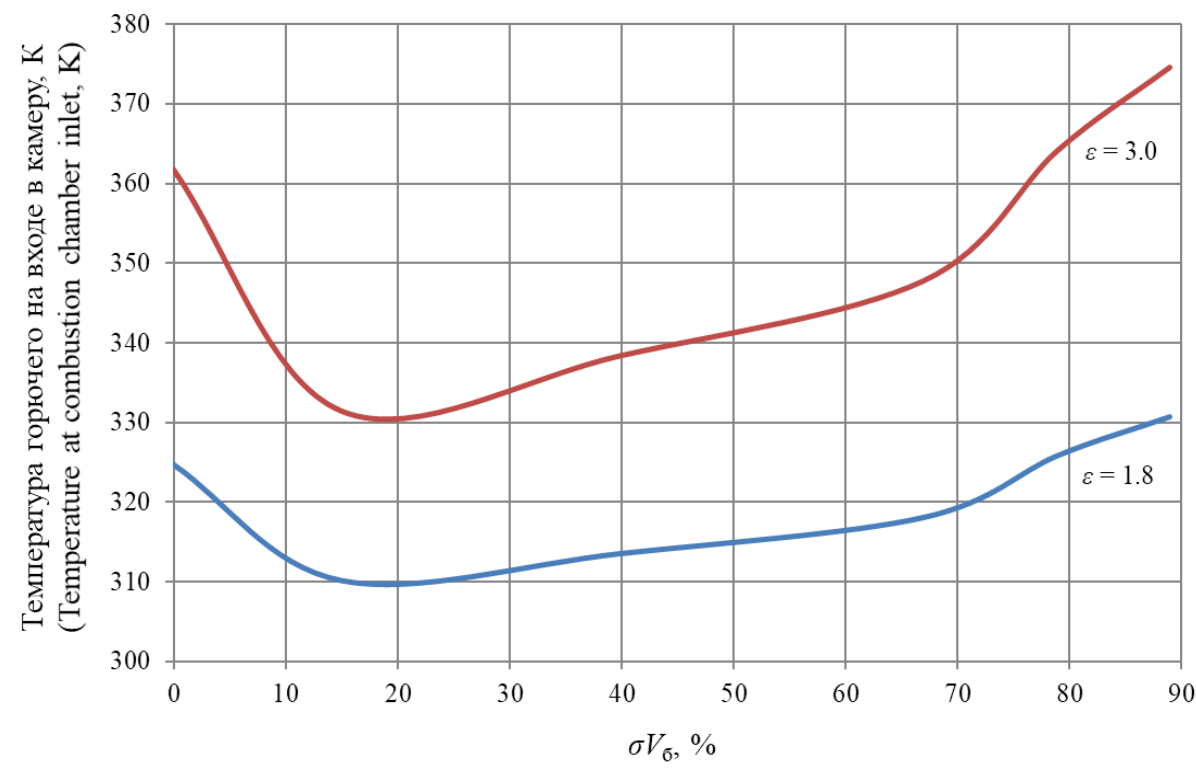

Рис.4. Влияние балластирующих компонентов на температуру топливного газа на входе КС. ${ }^{10}$

На рисунке 5 представлены графические зависимости $\alpha_{\text {гту }}$, определяемые по параметрам энергоустановки, от содержания балластирующих компонентов в составе НГ для газотурбинных энергоустановок с двумя типами турбокомпрессоров со степенями сжатия $\varepsilon=1.8$ и $\varepsilon=3.0$.

Анализ данных на рисунке 5 показывает, что нелинейная зависимость $T_{\text {гор.вх }}^{\text {кс }}=f\left(\sigma V_{\text {б }}\right)$ оказывает сильное влияние на потребные

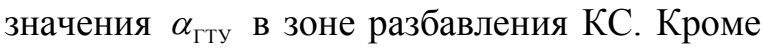
того, сильное влияние оказывает состав топливного газа. При содержании балластирую- щих компонентов более $70 \%$ для обеспечения заданной температуры на входе в турбину $T_{\text {газвв }}^{\mathrm{T}}=1200 \mathrm{~K}$ потребное значение расхода топливного газа $\dot{m}_{\text {гор }}$ возрастает так сильно, что это приводит к уменьшению $\alpha_{\text {гту }}$. Исследование зависимостей на рисунке 5 также показывает, что на разных месторождениях (разные составы НГ) требуется подбором расходов воздуха $\dot{m}_{\text {ок }}$ и топливного газа $\dot{m}_{\text {гор }}$

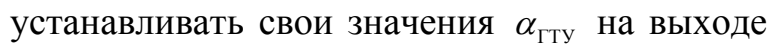
из КС для поддержания заданной температуры на входе в турбину $T_{\text {газ.вx }}^{\mathrm{T}}$. При этом значе- 
ние коэффициента избытка воздуха в зоне горения $\alpha_{1}$ остается неизменным.

Расходные характеристики воздуха и топливного газа для энергоустановки в целом и их распределение по зонам горения зависят от заданной мощности $N_{\text {пол}}$, коэффициента избытка воздуха на выходе из камеры сгора-


зоне горения $\alpha_{1}$.

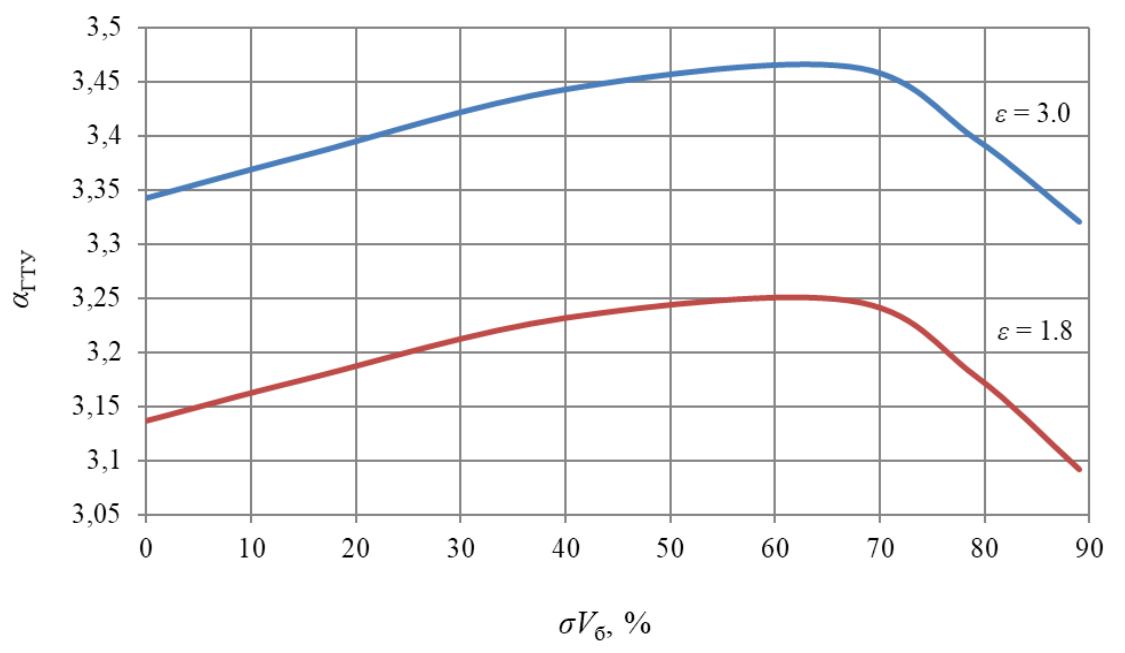

Рис.5. Влияние балластирующих компонентов на коэффициенты избытка воздуха $\alpha_{\Gamma т у .}{ }^{11}$

На рисунке 6 приведены потребные массовые расходы: рабочего тела через турбину $\dot{m}_{\text {газ }}$ воздуха $\dot{m}_{\text {ок }}$, первичного воздуха в зоне горения $\dot{m}_{\text {ок1 }}$, вторичного воздуха в зоне разбавления $\dot{m}_{\text {ок2 }}$ и горючего в зоне горения $\dot{m}_{\text {гор }}$ для газотурбинных энергоустановок с двумя типами турбокомпрессоров со степенями сжатия $\varepsilon=1.8$ и $\varepsilon=3.0$ и мощностного ряда $N_{\text {пол }}=100$ кВт и $N_{\text {пол }}=200$ кВт при утилизации НГ с разным содержанием балластирующих компонентов.

Анализ зависимостей на рисунке 6 показывает, что на разных месторождениях (разнородные НГ с различным содержанием балластирующих компонентов) требуется настройка регуляторов суммарного расхода воздуха и топливного газа для заданных турбокомпрессора и электрогенератора для выработки НГ заданного состава. Распределение воздуха в первичную и вторичную зоны внутри КС осуществляется в соответствии с геометрическими размерами узлов подачи.

При утилизации разнородных забалластированных НГ особое внимание необходимо уделить вопросам устойчивого положения фронта пламени в универсальной КС. Исследования газодинамики горения нефтяных газов разного состава показали, что для устойчивого положения фронта пламени требуется определенное соотношение между среднерасходной скоростью горюче-воздушной смеси и скоростью турбулентного горения. Для определения диаметра камеры, обеспечивающего устойчивое положение фронта пламени, предлагается использовать в качестве обобщенного параметра рабочего процесса относительную расходонапряженность, которая должна находиться в диапазоне $g_{\text {К }}=(0.8 \ldots 2.5) \cdot 10^{-4} \mathrm{\kappa г} / \mathrm{c} \cdot \mathrm{H}$.

На рисунке 7 приведены минимальные и максимальные значения диаметров камеры, обеспечивающие устойчивое положение фронта пламени, для газотурбинных энергоустановок с двумя типами турбокомпрессоров со степенями сжатия $\varepsilon=1.8$ и $\varepsilon=3.0$ и мощностного ряда $N_{\text {пол }}=100$ кВт и $N_{\text {пол }}=200$ кВт при утилизации НГ с разным содержанием балластирующих компонентов.

Анализ данных на рисунке 7 показывает, что для газотурбинной энергоустановки с заданным турбокомпрессором и электрогенератором существует возможность использования универсальной камеры сгорания с постоянным диаметром при утилизации НГ с содержанием балластирующих компонентов до 70 \%. Следовательно, при определении геометрического облика универсальной камеры сгорания необходимо учитывать концентрационные пределы и газодинамические условия горения для обеспечения стабильного положения фронта пламени при утилизации нестандартных топливных газов разного состава и теплопроизводительности. 




a) $\varepsilon=1.8 ; N_{\text {пол }}=100$ кВт

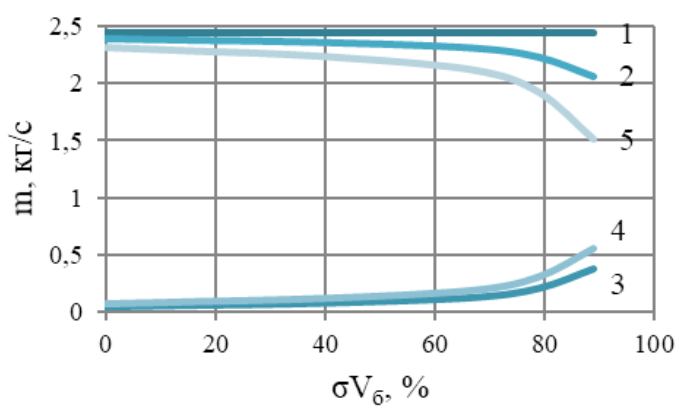

в) $\varepsilon=1.8 ; N_{\text {пол }}=200 \mathrm{\kappa BT}$

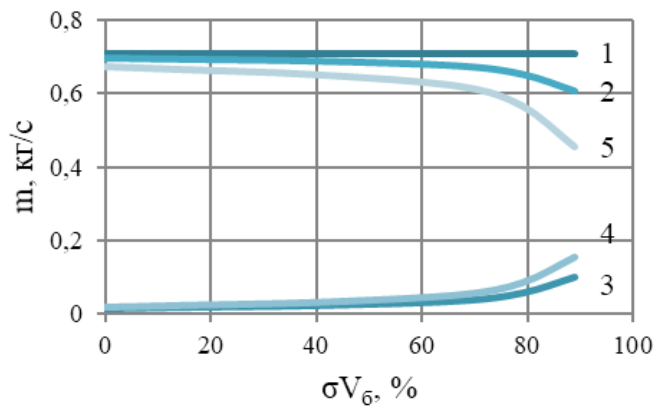

б) $\varepsilon=3.0 ; N_{\text {пол }}=100$ кВт

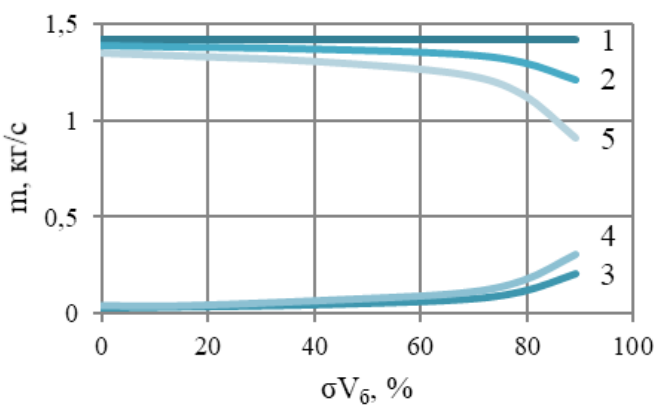

г) $\varepsilon=3.0 ; N_{\text {пол }}=200 \kappa \mathrm{Bт}$

1 -массовый расход рабочего тела через турбину; 2 - суммарный массовый расход воздуха; 3 -массовый расход горючего в зоне горения; 4 - массовый расход первичного воздуха в зоне горения; 5 -массовый расход вторичного воздуха в зоне разбавления.

Рис.6. Массовые расходные характеристики рабочего тела турбины, воздуха и топливного газа. ${ }^{12}$

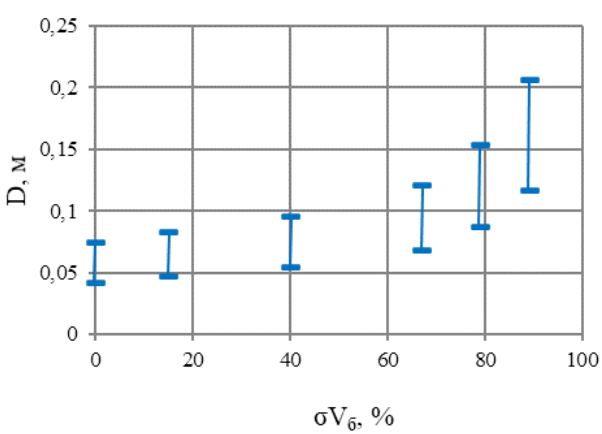

a) $\varepsilon=1.8 ; N_{\text {пол }}=100 \mathrm{\kappa BT}$

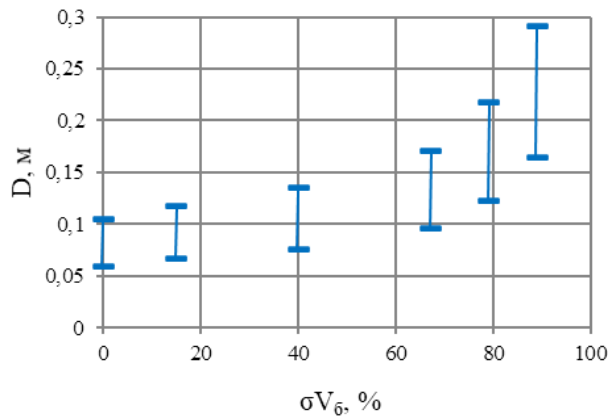

в) $\varepsilon=1.8 ; N_{\text {пол }}=200 \mathrm{\kappa BT}$

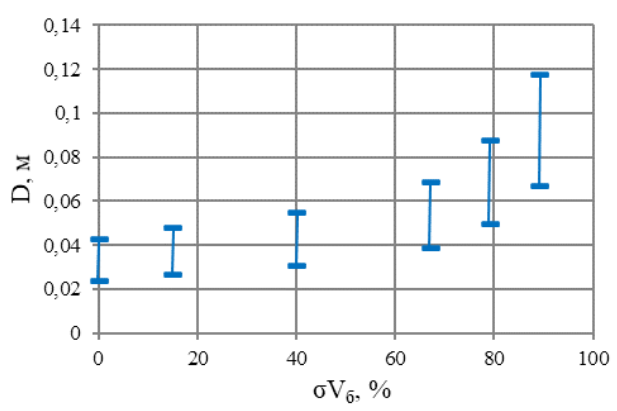

б) $\varepsilon=3.0 ; N_{\text {пол }}=100$ кВт

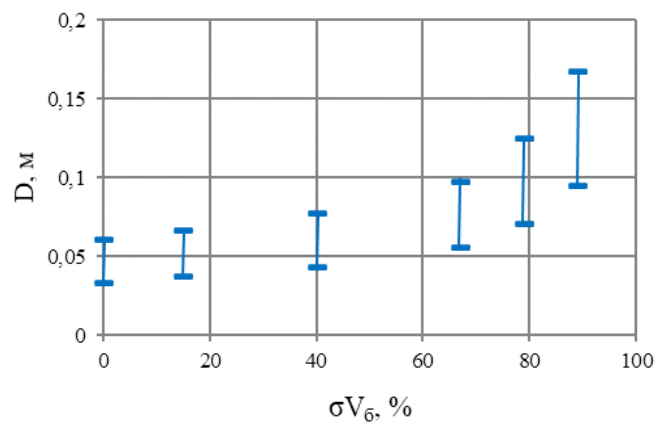

г) $\varepsilon=3.0 ; N_{\text {пол }}=200 \mathrm{\kappa BT}$

Рис.7. Возможные диаметры универсальной камеры сгорания для утилизации разнородных НГ. ${ }^{13}$ 


\section{ЗАКЛЮЧЕНИЕ}

При создании микрогазотурбинных энергоустановок нового поколения для утилизации нестандартных топливных газов требуется разработка двухзонных универсальных КС, которые обеспечивали бы устойчивое сгорание забалластированных топливных газов разного состава и теплопроизводительности. Для утилизируемых забалластированных газов предложено организовывать рабочий процесс в зоне горения при коэффициенте избытка воздуха $\alpha_{1}=1.5$, который находится в интервале между нижним и верхним концентрационными пределами горения. Коэффициент избытка воздуха на выходе из КС

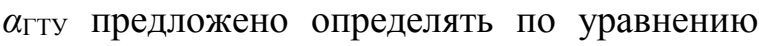
энергетического баланса. Представлены зави-

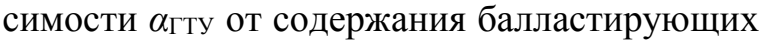
компонентов для турбокомпрессоров со степенями сжатия $\varepsilon=1.8$ и $\varepsilon=3.0$. Получены массовые расходные характеристики рабочего тела через турбину, воздуха в зоны горения и разбавления, топливного газа в зону горения при утилизации НГ с содержанием балластирующих компонентов до 80 \%. Получены возможные диаметры универсальных КС, при которых обеспечивается устойчивое положение фронта пламени при сжигании топливных газов разного состава и теплопроизводительности. Расчеты проведены для семейства турбокомпрессоров со степенями сжатия $\varepsilon=1.8$ и $\varepsilon=3.0$ и мощностного ряда $N_{\text {пол }}=100$ кВт и $N_{\text {пол }}=200$ кВт. Показана возможность использования универсальной КС с постоянными геометрическими размерами в составе микрогазотурбинных энергоустановок для утилизации топливных газов с содержанием балластирующих компонентов до $70 \%$.

\section{APPENDIX 1 (ПРИЛОЖЕНИЕ 1)}

${ }^{1,2}$ Table 1. Compositions of petroleum gases.

${ }^{3,4}$ Table 2. Thermochemical characteristics of petroleum gases.

${ }^{5}$ Fig.1. Influence of ballasting components on the mass stoichiometric ratio and heat output of petroleum gases.

${ }^{6}$ Fig.2. Influence of ballasting components on the concentration limits of combustion.

${ }^{7}$ Fig.3. Schematic diagrams of a micro-gas turbine power plant.

${ }^{8,9}$ Table 3. Calculated values of the excess air factor $\alpha_{G T P}$.

${ }^{10}$ Fig.4. Influence of ballasting components on the temperature of the fuel gas at the inlet of the combustion chamber.
${ }^{11}$ Fig.5. Influence of ballasting components on excess air coefficients $\alpha_{\mathrm{GTP}}$.

${ }^{12}$ Fig.6. Mass flow characteristics of the working fluid of the turbine, air and fuel gas (1 - mass flow rate of the working fluid through the turbine; 2 - total mass air flow; 3 - mass consumption of fuel in the combustion zone; 4 - mass flow rate of primary air in the combustion zone; 5 - mass flow rate of secondary air). ${ }^{13}$ Fig.7. Possible diameters of the universal combustion chamber for utilizing dissimilar petroleum gases.

\section{Литература (References)}

[1] Andrés Z.M., João A. de C. Jr., Christian R.C. Method for determination of flammability limits of gaseous compounds diluted with $\mathrm{N} 2$ and $\mathrm{CO} 2$ in air. Fuel, 2018, vol. 226, pp. 65-80.

[2] Liao S.Y., Cheng Q., Jiang D.M., Gao J. Experimental study of flammability limits of natural gas-air mixture. Journal of Hazardous Materials, 2005, vol. 119(1-3), pp. 81-84.

[3] Gan C., Zili L., Chao Y. Experimental study of flammability limits of methane/air mixtures at low temperatures and elevated pressures. Fuel, 2016, vol. 181, pp. 1074-1080.

[4] Wang T., Luo Z., Wen H., Cheng F., Deng J., Zhao J., Guo Z., Lin J., Kang K., Wang W. Effects of flammable gases on the explosion characteristics of $\mathrm{CH} 4$ in air. Journal of Loss Prevention in the Process Industries, 2017, vol. 49, part B, pp. 183-190.

[5] Zamashchikov V.V. On the Flammability Limit. Combustion Explosion and Shock Waves, 2018, vol. 54(4), pp. 393-397.

[6] Zhen H.S., Leung C.W. Cheung C.S., Huang Z.H. Characterization of biogas-hydrogen premixed flames using Bunsen burner. International Journal of Hydrogen Energy, 2014, vol. 39(25), pp. 13292-13299.

[7] Zhen H.S., Leung C.W., Cheung C.S. A comparison of the heat transfer behaviors of biogase-H2 diffusion and premixed flames. International Journal of Hydrogen Energy, 2014, vol. 39(2), pp. 1137-1144.

[8] Fei Teng. The Effect of Hydrogen Concentration on the Flame Stability and Laminar Burning Velocity of Hydrogen-Hydrocarbon-Carbon Dioxide Mixtures. PhD thesis [A thesis submitted to the Department of Chemical and Biological Engineering of the University of Sheffield, UK for the degree of Doctor of Philosophy], Sheffield, 2014, $268 \mathrm{p}$.

[9] Janus M.C., Richards G.A., Yip M.J., Robey E.H. [Effects of ambient conditions and fuel composition on combustion stability]. Proceedings of the ASME 1997 International Gas Turbine and Aeroengine Congress and Exhibition. Orlando, Florida, June 2-5, 1997, doi: 10.1115/97-GT-266. 
[10] Straub D., Ferguson D., Casleton K., Richards G. [Effects of propane/natural gas blended fuels on gas turbine pollutant emissions]. 5th US Combustion Meeting. San Diego. March 25-28, 2007.

[11] Rowhani A., Tabejamaat S. Experimental study of the effects of swirl and air dilution on biogas non-premixed flame stability. Thermal Science, 2015, vol. 19, no. 6, pp. 2161-2169, doi: 10.2298/TSCI130112157R.

[12] Meghdad Saediamiri, Meghdad Saediamiri, Madjid Birouk, Madjid Birouk, Kozinski J.A. Flame stability limits of low swirl burner - Effect of fuel composition and burner geometry. Fuel, 2017, vol. 208, pp. 410-422, doi: 10.1016/j.fuel.2017.07.028.

[13]Leung T., Wierzba I. The effect of hydrogen addition on biogas non-premixed jet flame stability in a co-flowing air stream. International Journal of Hydrogen Energy, 2008, vol. 33(14), pp. 3856-3862, 10.1016/j.ijhydene.2008.04.030.

[14] Lorenzo Figura, Jong Guen Lee, Bryan D. Quay, Domenic A. Santavicca. [The effects of fuel composition on flame structure and combustion dynamics in a lean premixed combustor]. Proceedings of the ASME Turbo Expo 2007: Power for Land, Sea, and Air. Volume 2: Turbo Expo 2007, Montreal, Canada, May 14-17, 2007, pp. 181-187, doi: 10.1115/GT2007-27298.

[15] Landry L., Halter F., Foucher F., Samson E., Mounaïm-Rousselle C. Effect of pressure and dilution on flame front displacement in boosted spark-ignition engine combustion. SAE Int. J. Fuels Lubr, 2009, vol. 1(1), pp. 984-992, doi: 10.4271/2008-01-1625.

\section{Сведения об авторах.}
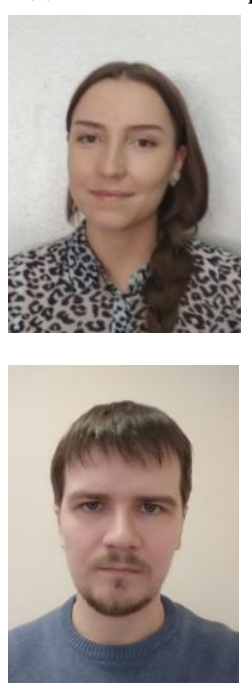

Шилова Алена Алексеевна инженер кафедры «Ракетнокосмическая техника и энергетические системы» ПНИПУ. Область научных интересов: рабочие процессы в КС ЭУ. E-mail: alyona1203@gmail.com

Матюнин Олег Олегович старший преподаватель кафедры «Ракетно-космическая техника и энергетические системы» ПНИПУ. Область научных интересов: численное моделирование рабочих процессов в ЭУ.

E-mail: matoleg@gmail.com
[16] Cala O.M., Meriño L., Kafarov V., Saavedra J. Effect of refinery gas composition on characteristics of combustion process. Revista Ingenierías Universidad de Medellín, 2013, vol. 12(23), pp. 101-111.

[17] Schulz O., Noiray N. Combustion regimes in sequential combustors: Flame propagation and autoignition at elevated temperature and pressure. Combustion and Flame, 2019, vol. 205, pp. 253268, doi: 10.1016/j.combustflame.2019.03.014.

[18] Rafał Slefarski. Study on the combustion process of premixed methane flames with $\mathrm{CO} 2$ dilution at elevated pressures. Energies, 2019, vol. 12(3), pp. 1-17, doi: 10.3390/en12030348.

[19] Jadeed Beita, Midhat Talibi, Suresh Sadasivuni, Ramanarayanan Balachandran. Thermoacoustic Instability Considerations for High Hydrogen Combustion in Lean Premixed Gas Turbine Combustors: A Review. Hydrogen, 2021, vol. 2(1), pp.33-57, doi: 10.3390/hydrogen2010003.

[20]Leung T., Wierzba I. Prediction of the blowout limits of turbulent non-premixed jet flames using the premixed combustion theory. Combustion Science and Technology, 2010, vol. 182(10), pp. 1528-1545, doi: 10.1080/00102200903462292.

[21] James C. Massey, Zhi X. Chen, Nedunchezhian Swaminathan. Lean Flame Root Dynamics in a Gas Turbine Model Combustor. Combustion Science and Technology, 2019, vol. 191, pp. 1019-1042, doi: 10.1080/00102202.2019.1584616.

[22] Inanc E., Proch F., Kempf A.M. Studying transient jet flames by high-resolution LES using premixed flamelet chemistry. Direct and LargeEddy Simulation XI. ERCOFTAC Series, 2019, vol. 25, pp. 237-243, doi: 10.1007/978-3-03004915-7_32.

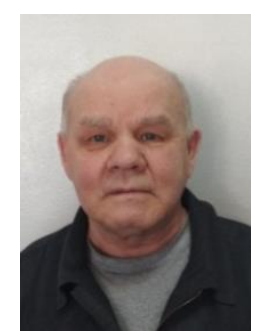

Бачев Николай Леонидович к.т.н., доцент кафедры «Ракетнокосмическая техника и энергетические системы» ПНИПУ. Область научных интересов: утилизационные газотурбинные установки.

E-mail: bn154@yandex.ru 